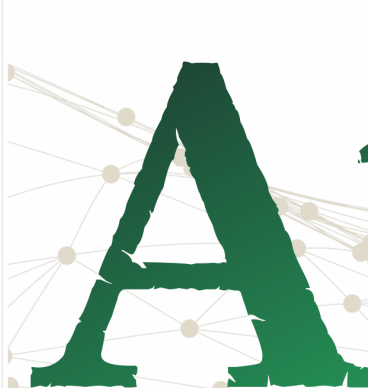

ISSN n² 2526-8031

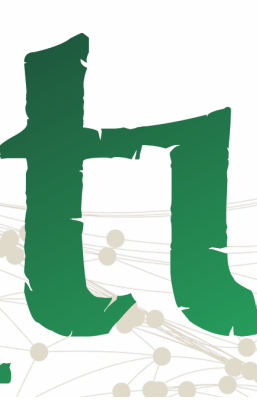

ura

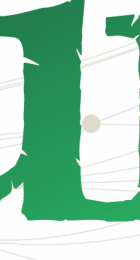

. rá

Vol. 3, n. 3, Setembro-Dezembro. 2019

\title{
OBRAS DE ARTE E OS PROCESSOS COMUNICATIVOS EM ESPAÇOS PÚBLICOS: ENTALHANDO IDENTIDADES
}

Works of Art and the communicative processes in public spaces: carving identities

Obras de arte y procesos comunicativos en espacios públicos: tallar identidades

\section{Tafinis Leandro Silva Said ${ }^{1}$ Leila Adriana Baptaglin ${ }^{2}$}

\section{RESUMO}

Este trabalho tem objetivo discutir os processos comunicacionais estabelecidos pelas obras de arte expostas em locais públicos como elementos de formação da memória e da identidade Roraimense. A história da produção e compra dos painéis pela Assembleia Legislativa foi investigada a partir de entrevistas orais com o artista. Seu conteúdo também foi submetido à análise com a finalidade de identificar e interpretar signos e símbolos trabalhados pelo autor. Tomando como base teórica estudiosos como Nora (1992) e Pollack (1993), observou-se que essa manifestação artístico-cultural, produzida por encomenda, embora não tenha seu conteúdo previamente definido pelos agentes detentores do poder político, faz coro ao seu discurso e atua conjuntamente na busca pela determinação dos símbolos e signos que deveriam representar Roraima e seu povo. Para além das lendas que o autor pretendeu retratar, as obras são representativas de um discurso de poder, remetendo à história e à composição social de Roraima num momento de afirmação da identidade local - a transição do status político de Território para Estado.

PALAVRAS-CHAVE: Arte; Comunicação; Identidade; Roraima.

\footnotetext{
1 Mestranda do curso de pós-graduação em comunicação da Universidade Federal de Roraima. E-mail: tafinissaid@hotmail.com

2 Pós-Doutora em Filosofia e Ciências Humanas em Nuestra América/VZ; Doutora em Educação/UFSM. Professora do Curso de Licenciatura em Artes Visuais/UFRR. E-mail: leila.baptaglin@ufrr.br
} 


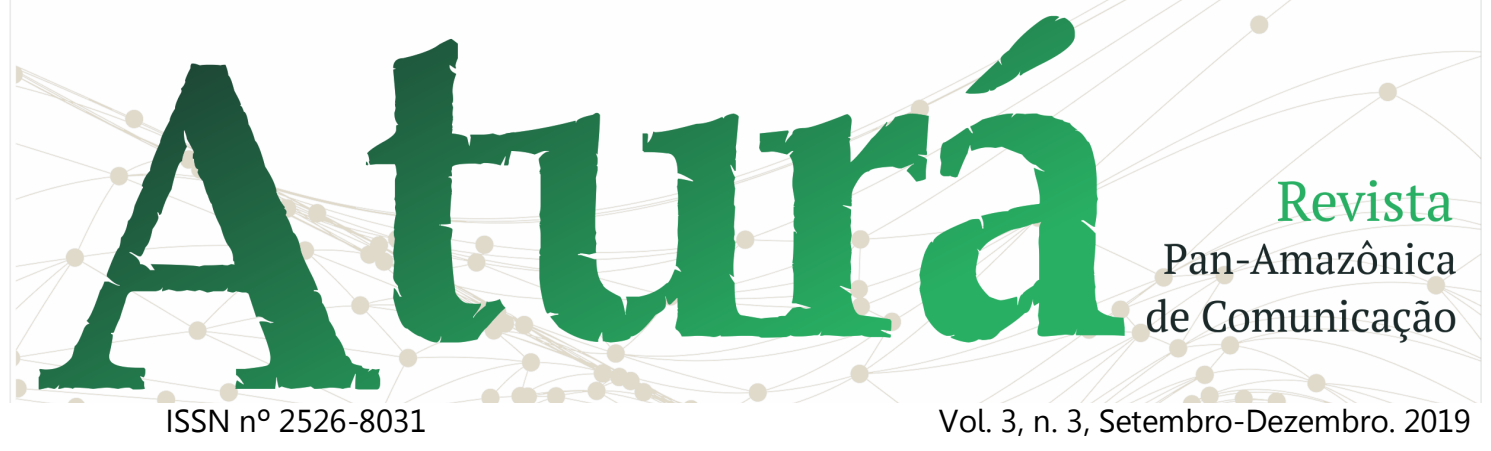

\begin{abstract}
This paper aims to discuss the communicational processes established by works of art exhibited in public places as elements of Roraimense memory and identity formation. The history of the production and purchase of the panels by the Legislative Assembly was investigated from oral interviews with the artist. Its content was also submitted to analysis in order to identify and interpret signs and symbols worked by the author. Taking as theoretical base scholars such as Nora (1992) and Pollack (1993), it was observed that this artistic-cultural manifestation, produced by order, although not previously defined by the agents holding the political power, is in line with their discourse and acts jointly in the search for the determination of symbols and signs that should represent Roraima and its people. Beyond the legends the author intended to portray, the works are representative of a discourse of power, referring to the history and social composition of Roraima in a moment of affirmation of local identity - the transition of political status from Territory to State.
\end{abstract}

KEYWORDS: Art; Communication; Identity; Roraima.

\title{
RESUMEN
}

Este artículo tiene como objetivo discutir los procesos comunicacionales establecidos por las obras de arte exhibidas en lugares públicos como elementos de la memoria roraimense y la formación de la identidad. La historia de la producción y compra de paneles por parte de la Asamblea Legislativa fue investigada a partir de entrevistas orales con el artista. Su contenido también se sometió a análisis para identificar e interpretar signos y símbolos trabajados por el autor. Tomando como base teórica a académicos como Nora (1992) y Pollack (1993), se observó que esta manifestación artístico-cultural, producida por orden, aunque no previamente definida por los agentes que detentan el poder político, está en línea con su discurso y actúa conjuntamente en la búsqueda de la determinación de los símbolos y signos que deben representar a Roraima y su gente. Más allá de las leyendas que el autor pretendía retratar, las obras son representativas de un discurso de poder, que se refieren a la historia y la composición social de Roraima en un momento de afirmación de la identidad local: la transición del estatus político del Territorio al Estado. 


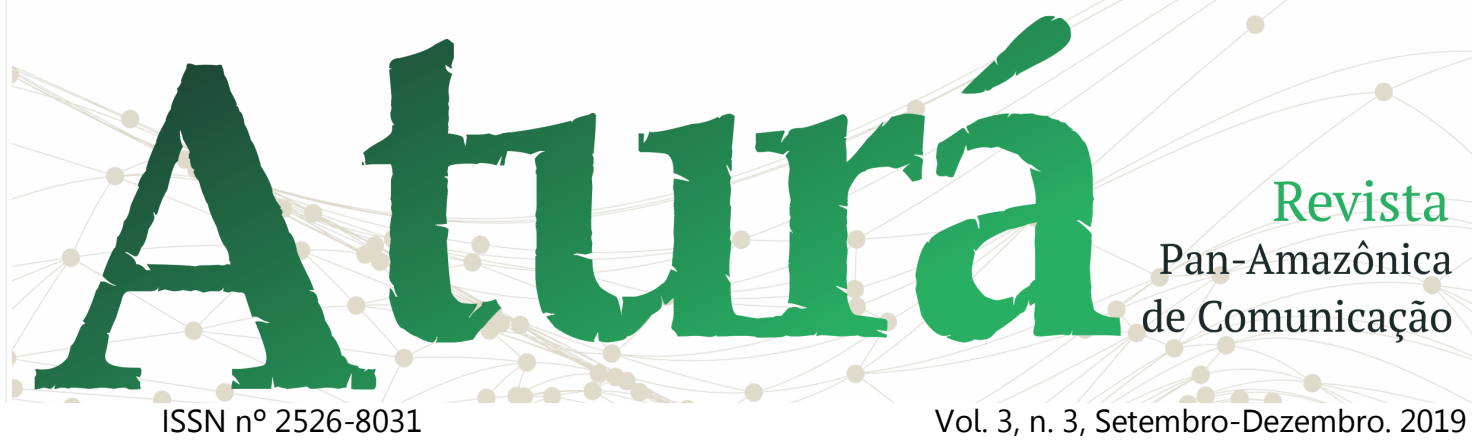

PALABRAS CLAVE: Arte; Comunicación; Identidad; Roraima.

Recebido em: 15.07.2019. Aceito em: 09.08.2019. Publicado em: 01.09.2019. 


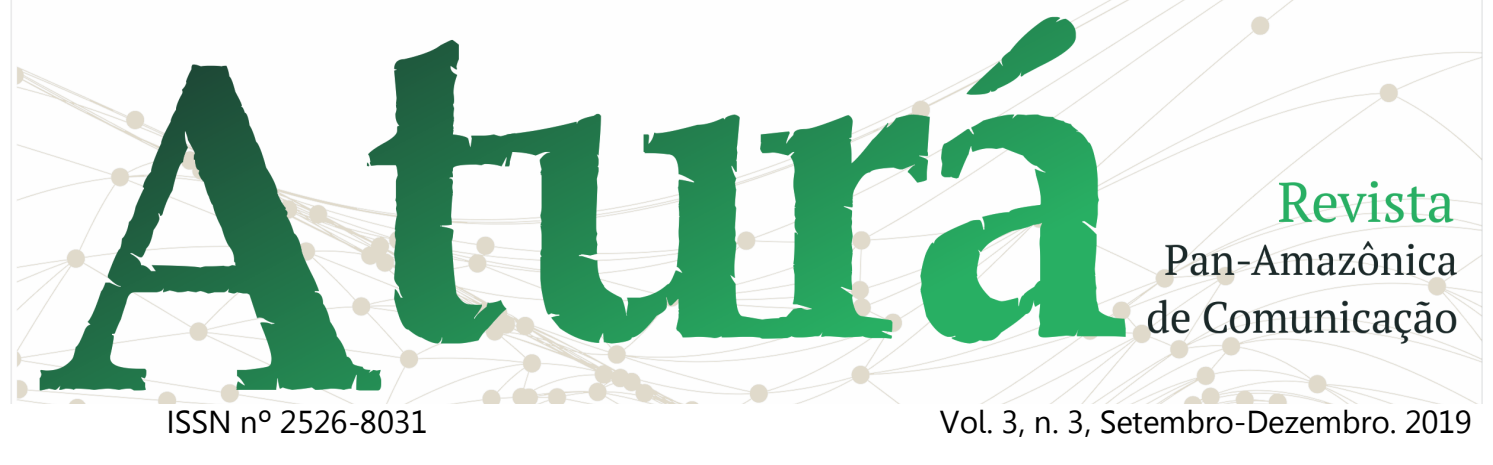

Introdução

Este trabalho é fruto de uma investigação sobre as obras de arte expostas no interior dos prédios de órgãos públicos da capital de Boa Vista Roraima. Em uma primeira investigação trabalhamos com os prédios da Assembleia Legislativa-ALE/RR, Palácio do Governo, Prefeitura Nova, Palácio da Cultura, entre outros.

No recorte deste artigo, será exposto uma reflexão epistemológica sobre pesquisa no campo da comunicação e arte, na qual Kuhn (1962) discute sobre a produção científica. Em seguida é apresentado uma descrição da obra de arte como objeto de estudo, materiais e técnicas utilizada pelo artista e sua biografia.

A análise de dados é realizada a partir de discussões da historiografia de Roraima a partir de autores como Martins (2010) e Freitas (2017) que problematizam o contexto histórico e político do prédio que abriga as obras. Também são realizadas discussões sobre cultura, identidade e memória de Roraima e como a arte se torna um meio de comunicar certos ideais voltados para a região. Referenciais teóricos como Nora (1992), Pollak (1993) e Canclini (1990) serão utilizados.

O objetivo do trabalho é discutir os processos comunicacionais estabelecidos pelas obras de arte expostas em locais públicos como elementos de formação da memória e da identidade Roraimense.

Para entender um determinado assunto posto como científico, costumase recorrer à livros, manuais que se apresentam como realizações científicas acabadas, compostos de teorias que explicam de maneira lógica, resultados quantitativos que parecem comprovar a existência ou funcionamento de algo. A teoria como elemento do conhecimento científico, demonstrou ser por muito tempo incontestável e imutável fazendo parte de um paradigma.

Dentro de um paradigma existem teorias e metodologias. Segundo Kuhn (1962, p.13), "paradigmas são realizações cientificas universalmente reconhecidas que, durante algum tempo, fornecem problemas e soluções modelares para uma comunidade de praticantes de uma ciência." Sendo assim, os paradigmas fazem parte da ciência.

A ciência normal ${ }^{3}$ não funciona sem paradigmas, inclusive ela pode ter vários paradigmas. Esta ciência normal encarada como ciência conservadora tem tentado manter seus paradigmas vigentes na história da ciência. Esse paradigma para, Santos (2010) se apresenta como

\footnotetext{
${ }^{3}$ Ciência normal, significa a pesquisa firmemente baseada em uma ou mais realizações científicas passadas. (KUHN, 1962, p.29)
} 


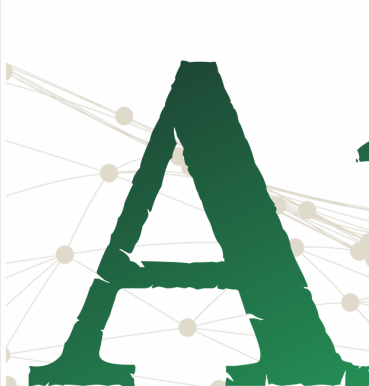

ISSN n²526-8031
Revista

Pan-Amazônica

de Comunicação

Vol. 3, n. 3, Setembro-Dezembro. 2019

dominante e traz uma visão reducionista da ciência onde muitas vezes são ignorados os vários campos de estudos e os conhecimentos científicos.

Cabe para este trabalho a reflexão de que as revoluções cientificas surgem da necessidade de quebra de paradigmas dessa ciência conservadora, uma revolução científica não nega o conhecimento anterior e sim pode ampliá-lo. Nesse sentido é necessário construir novas teorias para criar novos paradigmas para as várias ciências, inclusive para a ciência da comunicação e para a arte.

Cabe assim, um processo de reflexão epistemológico, que na ciência normal eram encarados de forma quantitativa e baseados na ideia de reduzir a complexidade dos conhecimentos existentes, mas agora, são construídos junto às propostas sociais e às variadas ciências.

Pesquisas que se articulam nas ciências sociais podem ser consideradas como pesquisas científicas, pois mesmo não tendo uma concepção mecanicista da natureza, onde o quantitativo é valorizado, elas podem caminhar para quebra de paradigmas ou constituir novos paradigmas científicos. Nas ciências sociais, as pesquisas qualitativas aproximam o sujeito, considera sua condição social, cultural, o conhecimento empírico para o fazer teórico.
É utilizado a aproximação da comunicação à arte, por entender que imagem é comunicação, representa algo. As imagens são construídas por vários meios, podendo advir da escrita linear, na qual o leitor constrói na memória imagens, ou na modalidade mais concreta da imagem visual, como a pintura, a fotografia ou vídeo. Essas imagens podem ser do tipo documental, ou imagens artísticas ${ }^{4}$, mas todas imagens produzidas são representações de uma realidade.

A "representação é um processo pelo qual se institui um representante que, em certo contexto limitado, tomará - lugar do que representa" (AUMONT,2012, p.104). Dessa forma, uma pintura ou fotografia representam uma determinada realidade que é reconstruída por quem a produz.

A arte tem uma capacidade de representação simbólica do mundo humano. Enquanto forma de expressão ela apresenta conceitos e características inerentes à cultura e ao homem. A partir dela $\mathrm{O}$ homem consegue expressar sentimentos, ideias, servindo como uma forma de comunicação conforme Júnior (2007). A arte nos ajuda a explicar e descrever a história, sua importância

4 Pinturas, esculturas, desenho, vídeo arte. Transmite a seu espectador, sob forma simbolizada, um discurso sobre o mundo real. (AUMONT,2012, P.272) 


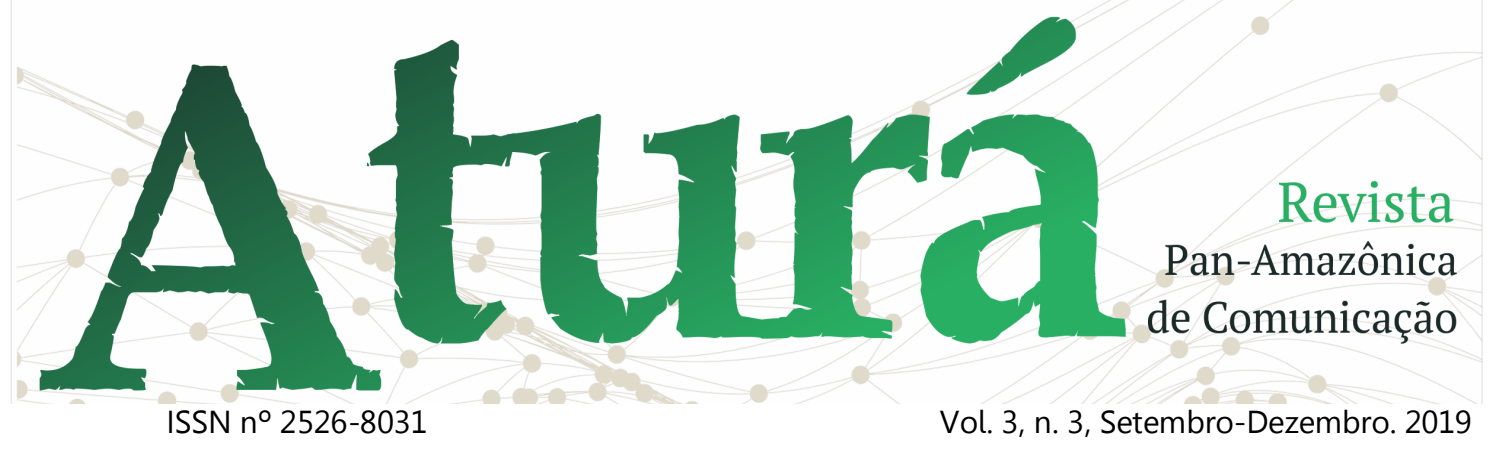

também está na capacidade oferecer à sociedade outra forma de comunicação e proliferação de sua cultura, como um processo contínuo e dinâmico.

Portanto, na análise de uma obra de arte, enquanto imagem representacional, devemos considerar a intenção do artista, pois é a partir de suas experiências, vivências, percepção e subjetividade, e a circunstância histórica, política, econômica e cultural do local que conseguimos entender o processo comunicativo estabelecido pela produção artística. Segundo Flusser (1920) as imagens são superfícies que representam algo dentro de um tempo e um espaço. As imagens são consequências de uma causa, fazem parte de uma determinada circunstância.

Para Lopes (2003) a pesquisa é a rigor um campo metodológico, a qual postulamos uma autonomia relativa, tanto porque possui regras internas de produção (estruturação metodológica $\mathrm{m}$ níveis e etapas) tanto porque se situa numa temporalidade própria. Neste caso, a metodologia exercida durante 0 processo da pesquisa foi de forma qualitativa por trabalhar com valores significativos de referência bibliográficas.

Segundo Gil (1994) afirma que a pesquisa qualitativa diferente da quantitativa, não se preocupa com representatividade numérica, mas, sim, com o aprofundamento da compreensão de um grupo social, dos valores implícitos, de uma organização, etc.

A escolha desta metodologia de trabalho vem por compreender que a pesquisa tem como característica o embasamento de reflexões acolhidas de livros e entrevistas, como forma de responder algumas questões pertinentes a esta investigação. Logo, essa troca de informações foi uma maneira de avaliar e considerar significados da comunicação, arte e identidade em Roraima, discursões sobre as produções de artistas, sobre conceitos e ideias acerca da arte como comunicação imagética, tendentes a colaborar na construção de uma pesquisa com contextos políticos e socioculturais. Este trabalho incorpora à pesquisa qualitativa, no que tange à análise dos elementos, contexto histórico e político, obra, artista e público.

Assim, a metodologia para este artigo utiliza a fases metodológicas de Lopes (2003), iniciando-se na definição do objeto; obra, artista e o prédio que se encontra. Em seguida vem a fase da observação que para Lopes (2003) essa se constitui a segunda faze da pesquisa empírica. Conforme a autora "visa uma reconstrução empírica da realidade, visa coleta, reunir evidências concretas capazes de produzir fenômenos no estudo no que eles têm de essencial" (LOPES, 2003, p. 142). A próxima fase é a descrição do objeto, na qual é realizado a 


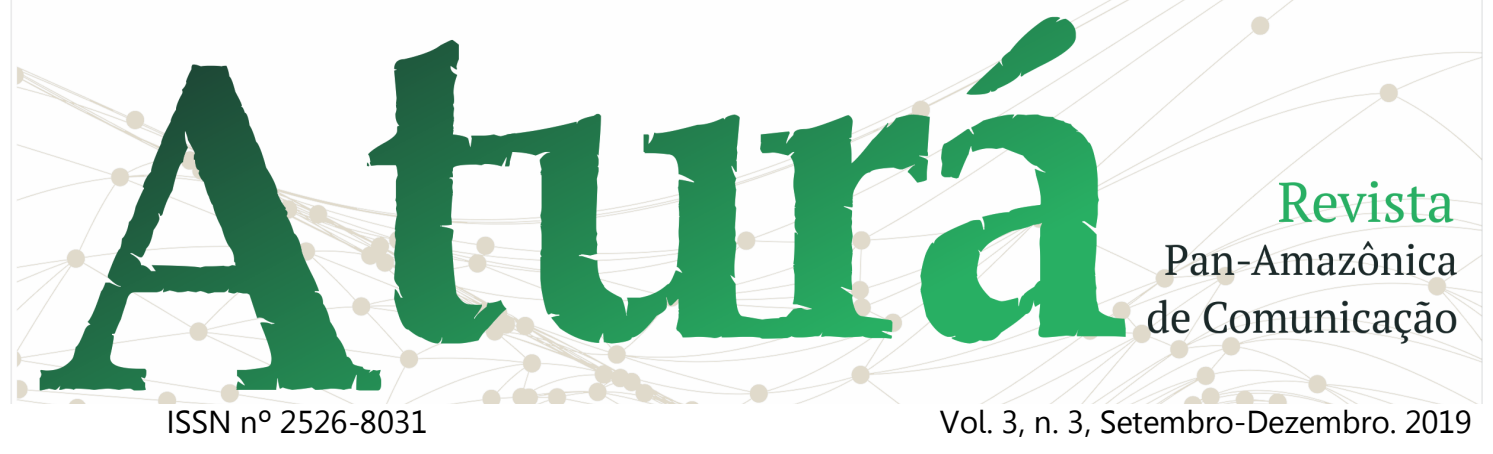

descrição da vida e obra do artista, bem como técnicas e materiais que trabalha, além do local em que suas obras são postas. Para Lopes (2003) a descrição faz a ponte entre a fase de observação dos dados e a fase de interpretação.

A segunda etapa da análise é a intepretação, dados sobre a história e política em Roraima os conflitos e problemáticas na formação de identidade local, bem como a descrição do objeto de pesquisa são articulados, integrando todos em uma totalidade. São apresentados apontamentos acerca das tensões simbólicas e o valor da obra de arte e seu espaço social, fundamentada na discursão entre referenciais teóricos que abordam, cultura, memória, identidade, comunicação e arte.

Nesta etapa aparece como elemento importante para produção das interpretações a análise de conteúdo enquanto ferramenta metodológica principal. Para Bardin (2002) a análise de conteúdo é um conjunto de técnicas de análise das comunicações. A autora afirma que existem várias formas de comunicação, dentre elas, a produção imagética, exemplo a Arte.

Com base no estudo da Arte, imagem e comunicação é possível estabelecer uma metodologia de pesquisa teórica. Com a análise de conteúdo segundo Bardin (2002) é possivel reinterpretar as mensagens e atingir uma compreensão de seus significados num nível que vai além de uma leitura comum.
A leitura efetuada pelo analista, do conteúdo das comunicações não é, ou não é unicamente, uma leitura "à letra", mas antes o realçar de um sentido que se encontra em segundo plano. Não se trata de atravessar significantes para atingir significados, à semelhança da decifração normal, mas atingir através de significantes ou de significados (manipulados), outros "significados" de natureza psicológica, sociológica, política, histórica, etc. (BARDIN, 2002,_p.41).

Neste sentido, a análise de conteúdo busca $\mathrm{o}$ processo de categorização compreender o conteúdo presente nos dados coletados na investigação.

\section{Descrição do artista e obra de arte}

Segundo Burke (2004), o termo cultura costumava se referir às artes e às ciências. Depois o termo foi utilizado para descrever seus equivalentes populares como; música folclórica, medicina popular e assim por diante. Já na última geração, passou a se referir à uma ampla gama de artefatos como imagens, ferramentas, além das práticas como, conversar, ler, jogar etc.

Como visto na história cultural, o termo cultura não pode ser dado de forma uniforme ou homogenia, pois 


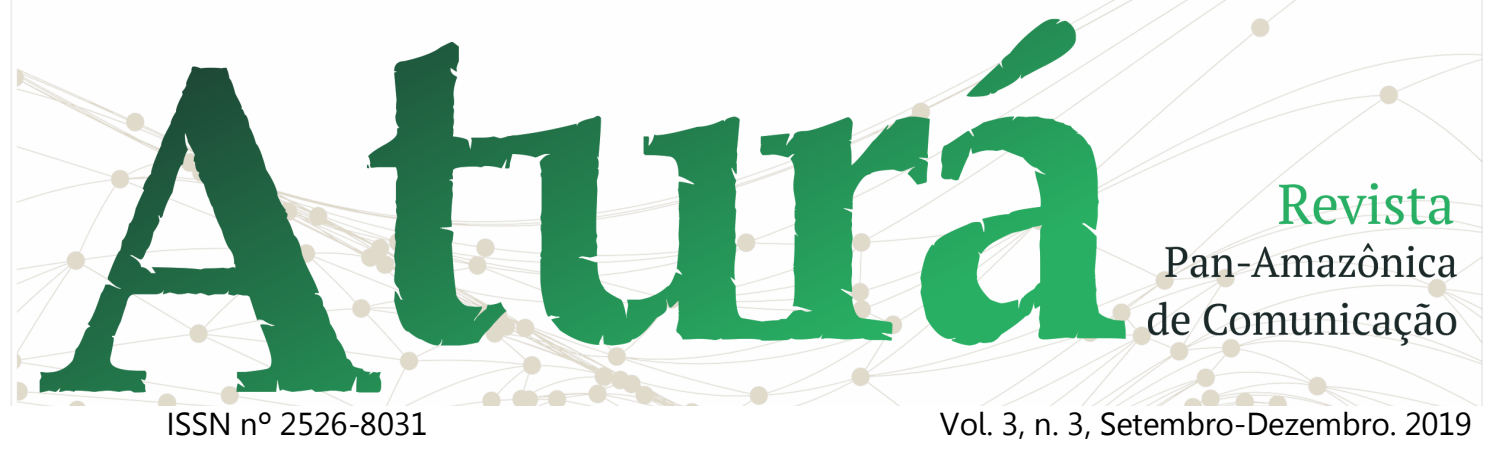

Burke (2004) mostra que as abordagens sobre cultura até mesmo as realizadas pelos historiadores, mudam de acordo com as circunstâncias em que lhes são apresentadas, constituindo em relações de poder, tensões sociais, interesses até mesmo individuais e ideológicos, que perseguem o campo conceitual do que seria cultura.

O objeto de estudo da pesquisa são três painéis entalhados e pintados em madeira, com grandes dimensões $(3 \times 4 \mathrm{~m}$, $3 \times 8 \mathrm{~m}, 3 \times 8 \mathrm{~m})$ e expostos no hall de entrada e no corredor do prédio da Assembleia Legislativa de Roraima. Embora não se observe assinatura visível nos trabalhos, seu autor é o artista Cleodon Marques Farias, mais conhecido como Farias.

Farias é paraibano da cidade de João Pessoa e se mudou para Roraima em1976. Hoje tem 64 anos de idade. Grande parte de suas obras foram fixadas em paredes de prédios públicos e lá ficam por muito tempo. Sua técnica artística é o entalhe, que consiste na arte de entalhar ou cortar a madeira, transformando um desenho simples em relevo. A madeira do painel é esculpida com as técnicas de alto e baixo relevo.

$\mathrm{Na}$ técnica do alto relevo, a madeira é tirada ao redor do desenho, fazendo com que ele fique acima do suporte. Já na técnica de baixo relevo, a madeira é retirada na região exata do desenho que se quer fazer.

A madeira que o artista Cleodon Farias utiliza para a produção de painéis é o cedro. O Cedro, Cedrela r̈issilis pertence à família das Meliáceas, são árvores de grande porte e que produzem uma madeira de boa qualidade, muito valorizada no mercado. Os lugares de maior ocorrência no Brasil são na Amazônia, Acre, Amapá, Amazonas, Bahia, Espírito Santo, Mato Grosso, Minas Gerais, Pará, Rondônia, Santa Catarina, São Paulo (MENDOZA; BORGES; SILVA, 2015).

As ferramentas que Cleodon Farias utiliza na produção de suas obras são as goivas e formões servindo para fazer o corte no entalhe de madeira, às vezes utiliza um martelo para ajudar na perfuração com os formões na madeira. As goivas são bem parecidas com os formões, porém tem formato mais curvo para trabalhos com detalhes arredondados. As limas servem para remover rebarbas de madeira excedente, já as lixas são utilizadas para o dar um acabamento, deixando o objeto mais liso e pronto para receber o verniz ou pintura.

Figura 01 - Obras no hall do prédio Assembleia Legislativa 


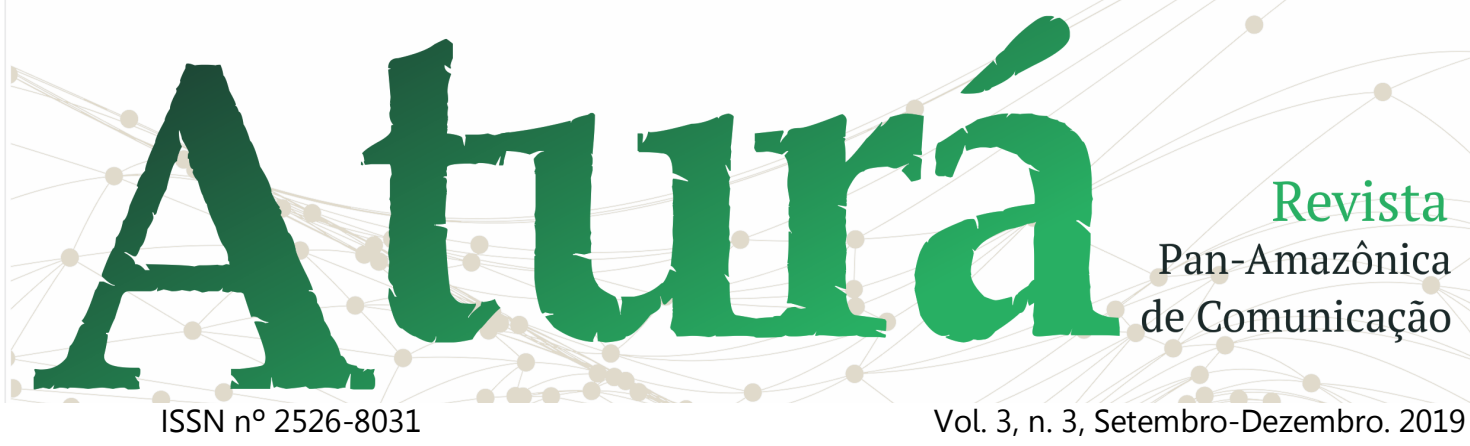

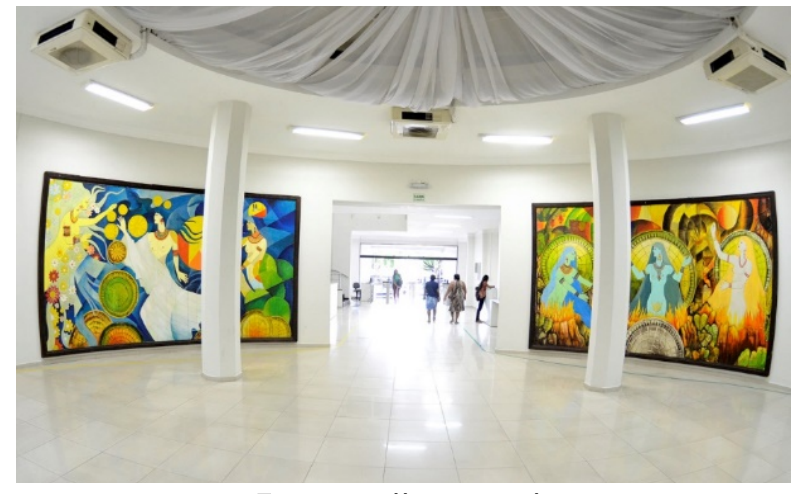

Foto: Wellmar Roth

Sobre a temática das obras, o artista afirma que prefere tratar de "temas amazônicos" nos seus painéis e que sua trajetória artística já demonstrava uma certa frequência nessa temática. Segundo ele, "meus temas sempre foram ligados ao cotidiano [...], a fauna e a flora, aos costumes indígenas, e os temas amazônicos" (FARIAS, 2016).

Em uma entrevista realizada em 2016 Farias conta que os painéis presentes no prédio na ALE-RR esclareceu que cada um dos painéis retrata lendas amazônicas: lenda da Mãe d'água, do Tepequém e a da Cruviana. Foram pintados com cores vibrantes de acordo com o tema. O amarelo escolhido para lembrar o fogo e calor do vulcão referente à lenda do Tepequém. Tons de azul para lembrar o vento e frio da noite na representação da Lenda Cruviana. Variações de verde e azul para representar a lenda da Mãe d'água.

\section{Análise dos processos comunicativos das produções artísticas}

É possível observar que os painéis de madeira do artista Cleodon Farias produzem sentidos, articulado a outros elementos que interagem com a história de Roraima no período em que os painéis foram produzidos. Podem ser analisados como um sistema de representação da cultural local.

De fato, as obras de artes fazem parte dos variados meios de produções culturais da nossa sociedade. No período entre 1800 a 1950 considerado como "História cultural Clássica" por Burke (2004), as artes eram estudadas por historiadores culturais na qual buscavam um certo "espírito da época" e essas obras de artes eram interpretadas a partir de livros, manuais, e referenciais da época, como por exemplo a Bíblia. "Seus praticantes liam, pinturas, poemas, etc. específicos como evidência da cultura e do período em que foram produzidos" (BURKE,2004, p.17). Visto isso, é evidente que as obras de arte já serviam como meio de compreensão dos processos culturais da nossa sociedade.

O ano de 1974 um prédio é concluído no centro e da capital de Boa Vista - Roraima, segundo Martins (2010) a obra abrigaria a biblioteca pública, um grande auditório em um museu, mas em 1988 o prédio foi fechado para reforma e 


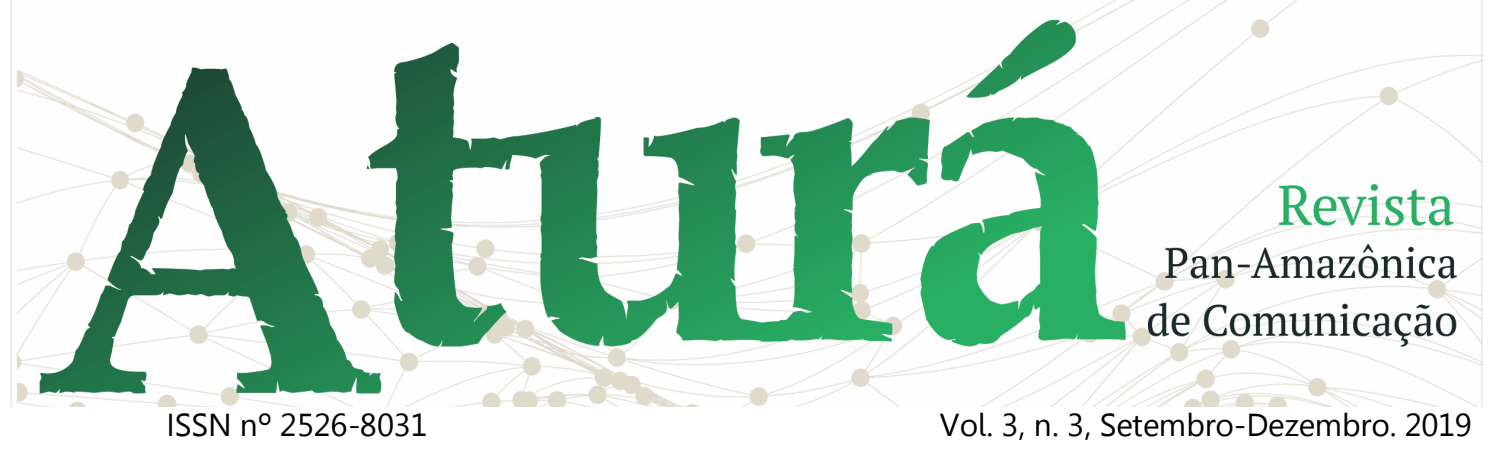

públicos é um trabalho com a memória, uma memória que também pode ser manipulada por aqueles que são agentes do poder e que veem na arte e nos artistas um meio de para representar seus ideais.

Pollak (1992) esclarece que a memória e a identidade são valores que geram disputas em conflitos sociais opondo grupos políticos diversos que buscam representar a si e aos outros. Nora (1993) reflete sobre esses processos de representatividade através de um olhar da memória sobre a história. Nora ensina que,

\begin{abstract}
À medida em que desaparece a memória tradicional, nós nos sentimos obrigados a acumular religiosamente vestígios, testemunhos, documentos, imagens, discursos, sinais visíveis do que foi, como se esse dossiê cada vez mais prolífero e devesse se tornar prova (NORA,1993, p.15).
\end{abstract}

Para entender essa problemática, é possível abordar as obras de arte e o modo como ficam disponíveis para o público. Isso porque as obras trazem símbolos, imagens que possuem significados, ou seja, representam uma materialização da memória, aquilo que Nora (1993) chama de "estoque material daquilo que é impossível lembrar, algo insondável daquilo que poderíamos ter necessidade de nos lembrar".

Canclini (1990) vê a arte como um importante elemento cultural que vive entre tensões. Alguns artistas vão ao encontro ao sistema do mercado, e outros lutam pela distinção de sua produção em relação aos meios massivos. Assim, se por um lado os artistas também são agentes importantes sobre o imaginário de uma sociedade e ora fazem a reafirmação, ora desestruturam uma identidade sobre um caráter global, também os locais onde a arte fica exposta, mesmo sujeitos a muitas interferências, se convertem no que Nora (1993) chama de "lugares de memória".

O historiador explica que assim como nos tempos clássicos, em os maiores mantenedores de lugares de memória eram as grandes famílias, a igreja e o Estado, na contemporaneidade isso também vem acontecendo. Para Nora (1993), existem lugares de memória e os monumentos seriam alguns desses lugares. Nesse aspecto, a memória se caracteriza como "um fenômeno construído social e individualmente", podendo "ser herdada por meio da socialização política ou histórica" (POLLAK, 1992, p.02).

Pode-se afirmar que, por elementos do conteúdo presente nas obras bem como pelo modo como estão expostas, as obras do paraibano Farias reforçam o que se chama de representação local para identidade do Estado. A grande aceitação pode ter se efetivado pelo calor da tentativa de 


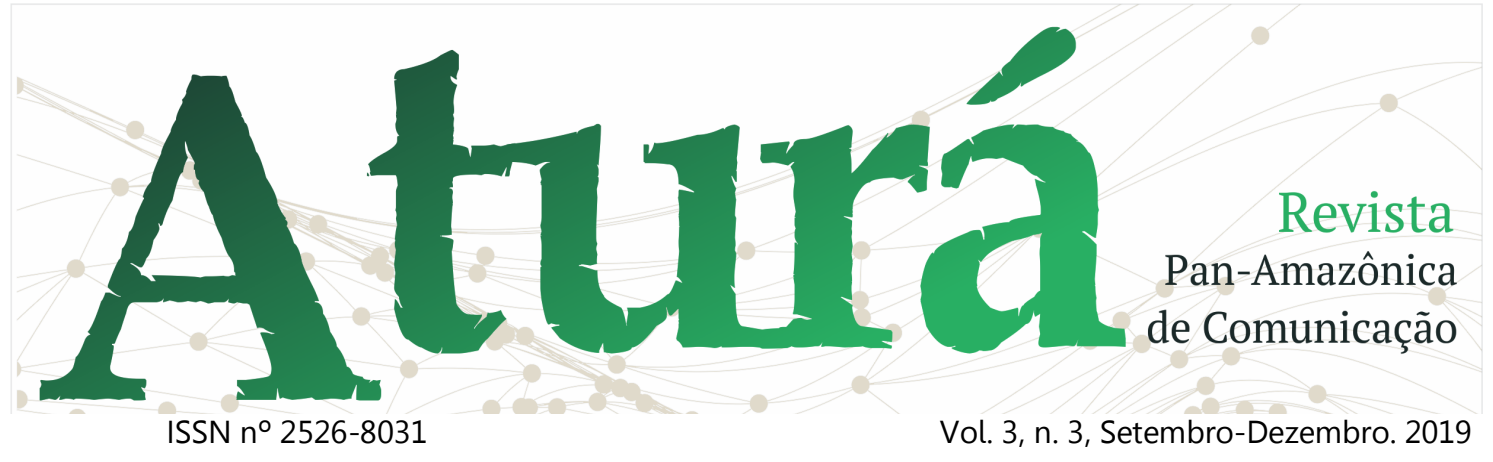

buscar uma identidade para região durante o período entre 1970 a 1990, uma identidade que mostra a presença indígena, seus elementos, comidas e lendas.

Os elementos presentes nas obras de Farias que estão, não somente nas obras da ALE-RR, mas também em outros prédios, apontam para o discurso de valorização da presença indígena no estado de Roraima, trazendo visualmente o exógeno ${ }^{6}$ da região amazônica (BUENO, 2002, p.169).

Para demonstrar esse caráter exógeno, ressaltamos a exuberância da natureza, compondo um caráter místico representado pelas lendas. Farias emoldura as cenas com rios, folhagens, flores e árvores. Essa estratégia reforça a sensação de se estar vendo uma capturada no interior da floresta, onde as personagens principais aparecem ainda cercadas de pássaros e peixes, além de desenhos estilizados circulares que lembram vitórias régias ou, por outra, troncos de árvore cortados.

É interessante observar que, nessas imagens circulares que $\mathrm{O}$ autor define como sendo "alegorias", por vezes se pode observar um traçado radial que remete ao formato do mapa da cidade de Boa Vista.

À primeira vista os painéis parecem compor uma única composição na qual figuram como centrais personagens representados por longilíneas e alvas figuras femininas, lembrando ninfas ou deusas. Essa possibilidade de leitura se acentua pelo fato de que nenhum deles possuem placa de identificação.

Figura 02 - Painel Lenda do Tepequém no Hall de entrada da ALE-RR.

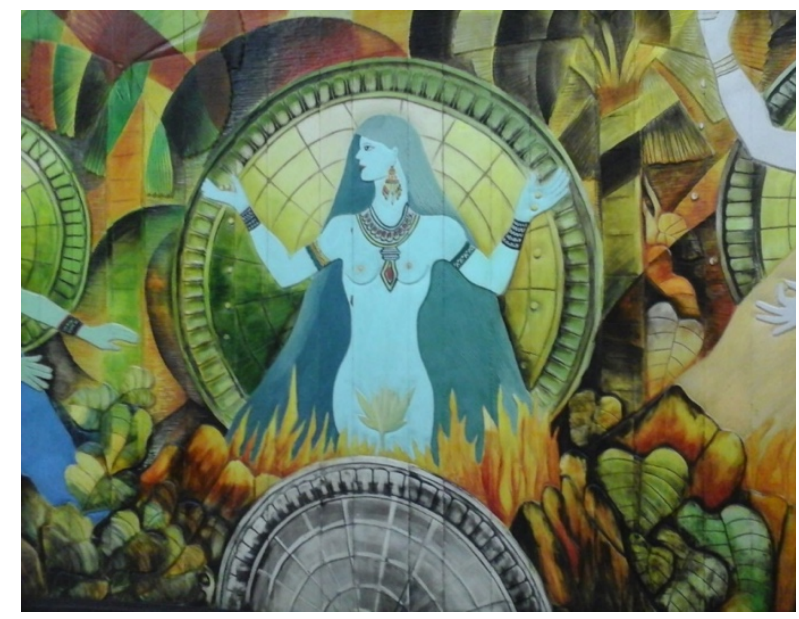

Foto: Wellmar Roth

\footnotetext{
${ }^{6}$ Magali Bueno (2002) cita que a visão exógena se refere à visão das pessoas que vivem fora da Amazônia tem sobre a região. E a visão endógena se refere à visão de pessoas que vivem na Amazônia tem sobre a região.
} 


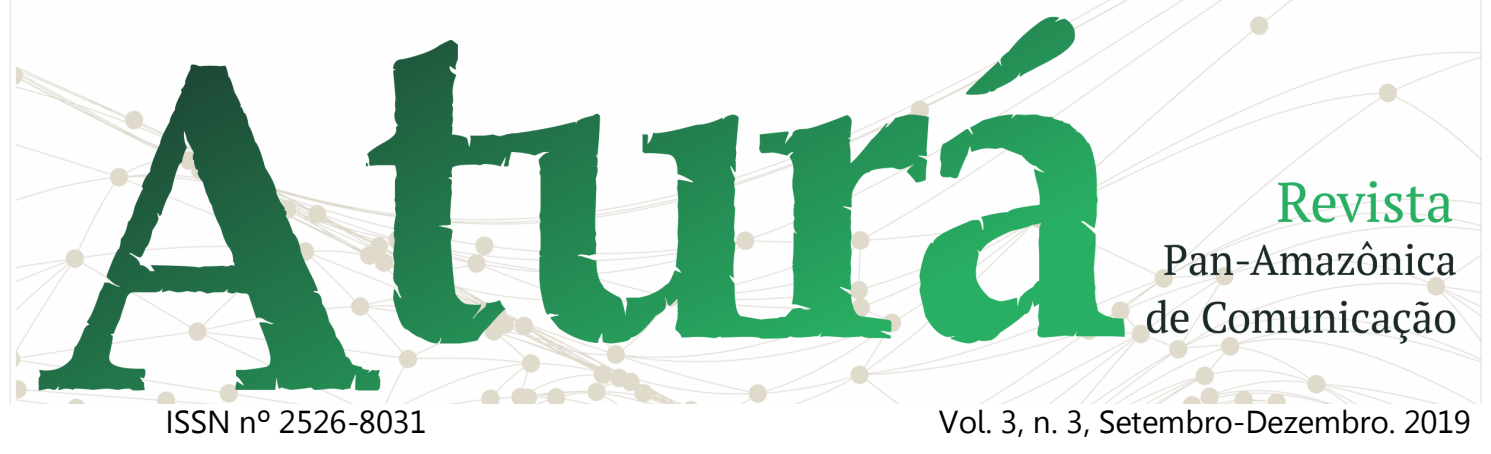

Figura 03 - Painel Mãe D'agua presente no corredor do prédio da ALE-RR

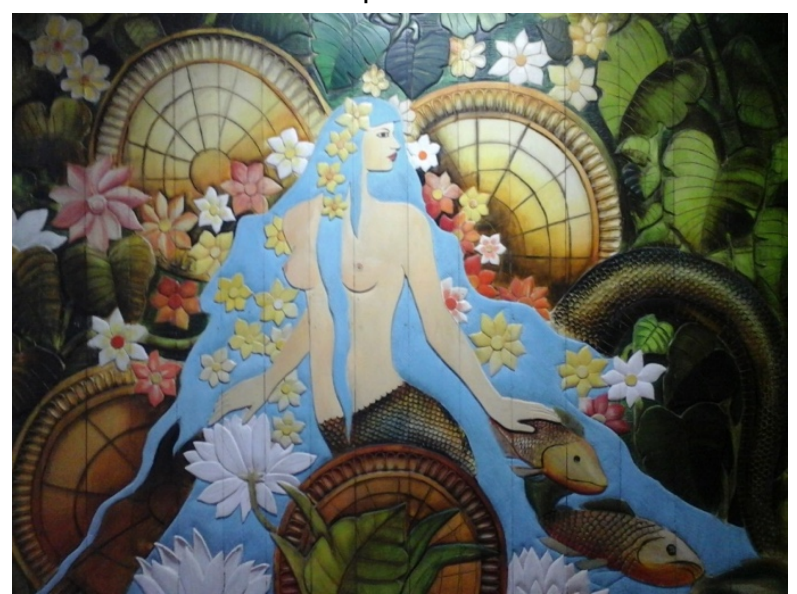

Foto: Wellmar Roth

Em entrevista concedida em 2016, o artista esclareceu que cada um dos três painéis retrata lendas amazônicas. Chamou a atenção, portanto, que os personagens centrais dessas lendas são originalmente indígenas, mas não estão assim representados com traços físicos iguais aos indígenas da região, a mulheres indígenas são representadas com peles claras, e por não ter nenhuma placa de identificação que apresente 0 título dos painéis, quem passa por esse local sente dificuldade de interpretar e reconhecer que se tratam de lendas indígenas.
Figura 04 - Painel Lenda Cruviana no Hall de entrada da ALE-RR

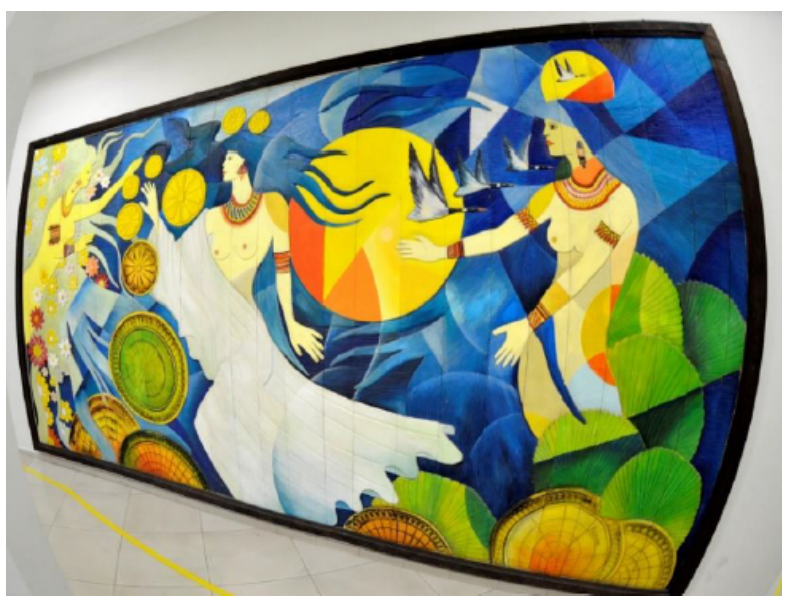

Foto: Wellmar Roth

Prédio da ALE-RR enquanto sede do legislativo do Estado, produz um discurso com caráter oficial por intermédio da atuação dos agentes políticos dessas casas, esse discurso pode servir tanto para a política quanto até mesmo para determinar um tipo de arte "oficial" transparecendo um certo apresso por umas e outras não. As obras de arte inseridas dentro de prédio públicos, possuem também importantes valores simbólicos que convivem entre relações de tensões.

Visto tanto os indígenas como sua cultura foram sendo manipulados pelos que aqui chegavam em Roraima, práticas como catequização de indígenas, servindo como mão-de-obra, como vaqueiro de fazendeiros das Fazendas Nacionais do Rei. "Todavia, a história 


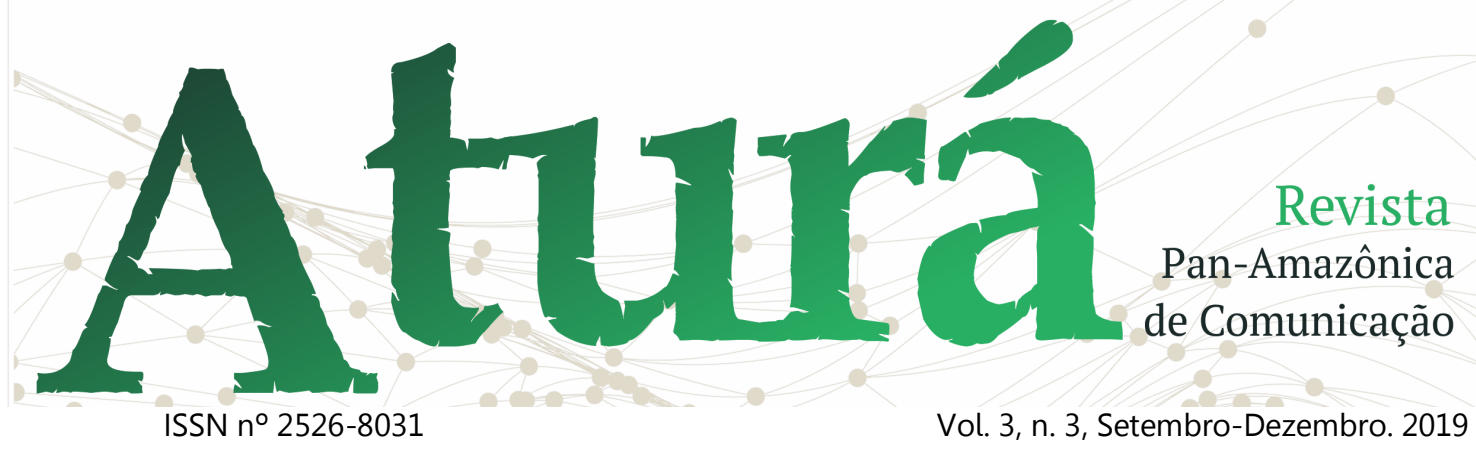

registra que os nativos não estavam satisfeitos com 0 processo de colonização. Isso provocou inúmeras revoltas entre os nativos, entre elas a Revolta da Praia de Sangue em 1790" (FREITAS, 2017, p.117).

Se levarmos em consideração essas narrativas conflituosas entre indígenas, colonizadores e fazendeiros presentes na história de Roraima, percebemos poucas mudanças no que diz respeito à conflitos atuais. Mesmo com o crescimento da preocupação com a questão ambiental a partir de 1980 como as ideias dirigidas para a preservação dos povos indígenas, da floresta e dos recursos naturais da área apontados por Magali (2002), a presença do índio na região vai perdendo cada vez mais espaço, de forma inconsciente ou intencional, muitos querem resistir ou até mesmo negar o papel do indígena na formação de Roraima.

Canclini (1990) entende que existem várias culturas e que algumas delas como as tradicionais consideradas locais e homogêneas que foram pouco comunicadas com o resto na nação, culturas que não estão em espaços urbanos, mas que passam pelo efeito dos sistemas que acompanham o mundo, muitas vezes não são ouvidas ou consideradas.

Com a produção de Farias e a utilização de temáticas regionais apresentando em suas obras a representação indígena retoma uma valorização para esses povos, a aceitação desses trabalhos em prédios pelos agentes políticos transparece a uma percepção de tentar apagar na história esse passado sombrio da relação em que os detentores da política local conflitavam com os indígenas e que agora querem comunicar por meio das artes ou um ideal identitário para região ou uma relação que agora se mostra harmoniosa e respeitosa com indígenas e sua cultura.

Sobre a aquisição dessas obras, Farias (2016) explica que se deu através de uma reunião na qual firmaram "acordo entre as partes", compostas por assessores dos chefes políticos e o artista. A ausência de registros oficiais da compra permite afirmar a falta de transparência do processo. Fruto de ações particulares em consonância com membros da elite local de políticos que formam o governo do Estado e da Prefeitura de Boa Vista.

Tal forma de aquisição de uma obra de arte não significa, portanto, a abertura de espaços públicos para a participação dos artistas e não pode ser entendida como fomento à produção artística local, o que demonstra que a presença de obras de arte nos espaços públicos da capital não pode ser lida como parte de uma política de valorização dessa produção. 


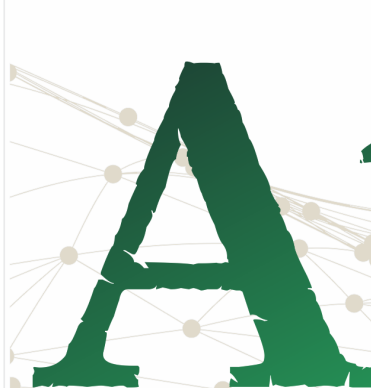

ISSN n² 2526-8031
Revista

Pan-Amazônica

de Comunicação

Vol. 3, n. 3, Setembro-Dezembro. 2019

\section{Considerações finais}

Tendo como proposta discutir os processos comunicacionais estabelecidos pelas obras de arte expostas em locais públicos como elementos de formação da memória e da identidade Roraimense, os painéis de Cleodon Farias também são um importante meio para analisar sobre conjunturas políticas, ideais de formação de identidade e outras problemáticas sobre a cultura roraimense. Assim, este trabalho propôs trazer reflexões sobre a história da capital Boa Vista Roraima e a construção de obras de arte que servem como lugares que comunicam contextos históricos, culturais e políticos na qual estão inseridas, onde as identidades são representadas marcando a memória coletiva da população não só de Boa Vista, mas aqueles que também visitam a capital.

Os painéis do Cleodon Farias trazem elementos da fauna, flora, indígenas, lendas e histórias de construção de Roraima, que embora apareçam como figuras e símbolos inconscientes e desprovidos de discurso aos receptores, essas obras podem revelar diversas situações sobre Roraima a partir também da análise da circunstância que a obra foi produzida. Essas reflexões nos despertam para a necessidade de prover um aprimoramento na capacidade dos observadores/receptores em alcançar uma comunicação visual com obras de arte.

É visto que a participação indígena na história Roraima sempre esteve presente nas mais diversas abordagens, hoje $\mathrm{o}$ estado tem quantidade de indígenas e comunidades que vivem no Estado, suas práticas e saberes, a natureza são elementos muito utilizado como forma de representatividade da cultura local. São temáticas locais muito bem estabelecidas por Farias que ganhou o "gosto" dos agentes políticos locais, com projetos bem aceitos para fixação de maneira permanente no interior dos prédios, questões essas que aponta para um valor simbólico dado aos painéis de Cleodon Farias pelos políticos do Estado.

Apesar de passarem por nós sem a devida inserção perceptiva, as imagens como as analisadas neste trabalho mostram uma mudança no tipo de objeto a ser exposto nas paredes dos prédios. As escolhas daquilo que será exposto dentro desses prédios, como os painéis de Cleodon Farias não foram escolhas inconsciente, de certa forma, relatam uma história e memória de um tempo e espaço.

As artes expostas em parede de prédios públicos também são artes que produzem sentidos; um sistema político ou não de representação cultural, visto que se percebe interesses dos políticos na 


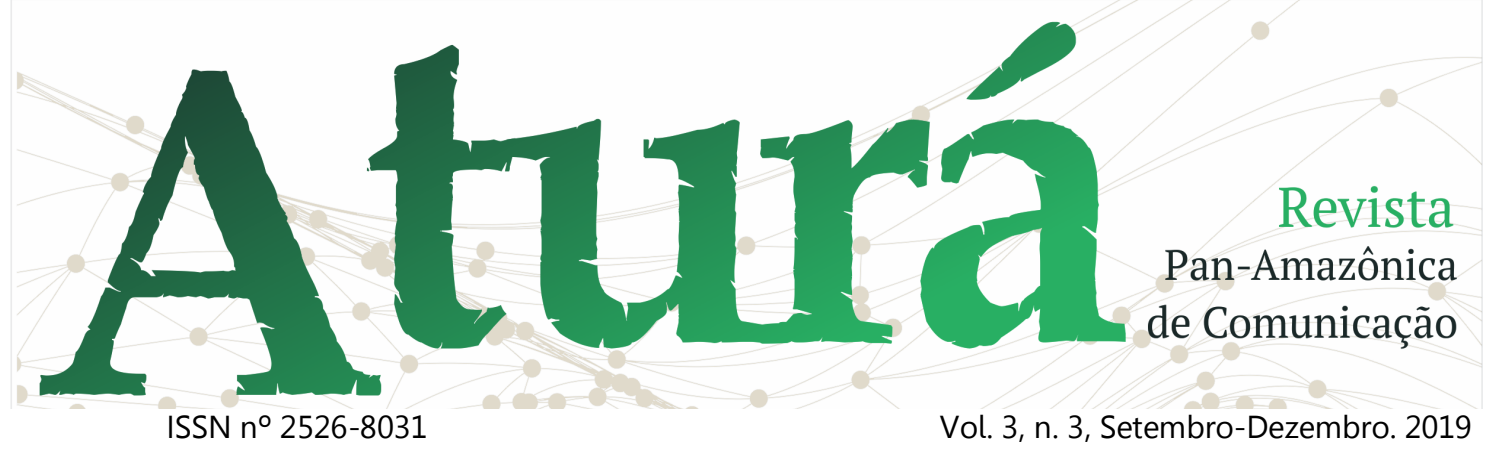

aquisição de obras, um interesse que pode ter uma intenção de ideal identitário e ou somente questões estéticas desinteressadas para 0 embelezamento do prédio.

Tais apontamentos nos servem para iniciar, portanto, uma discussão sobre o papel da que a arte pode ter em locais onde a disputa pela memória e pela formação identitária ainda se dá de modo muito acirrado. Para tanto, problematizamos os interesses do poder público na aquisição de obras de arte, com desdobramentos que fomentarão a continuidade da nossa pesquisa.

\section{Referências}

AUMONT, Jacques. A imagem. Trad. Estela dos Santos Abreu, Cláudio C. Santoro. Ed.16², São Paulo: Papirus,2012.

BAPTAGLIN, L. A.; RIBEIRO, A. DA S. A POÉTICA VISUAL DE ISAIAS MILIANO: Arte e Arqueologia na Amazônia. Revista

Observatório, v. 4, n. 2, p. 931-949, 1 abr. 2018.

BAPTAGLIN, L. A.; CHIERENTIN SANTI, V. J. As intervenções artísticas urbanas no circuito da arte em Roraima e o potencial comunicativo dos saberes artísticos amazônicos. Revista Observatório, v. 4, n. 4, p. 615-637, 29 jun. 2018.

BARDIN, Lourence. Análise de Conteúdo. Portugal: Edições 70 Lda,2002.

BUENO, Magali. $O$ imaginário brasileiro sobre a Amazônia: uma leitura por meio dos discursos dos viajantes, do Estado, dos livros didáticos, de Geografia e da mídia impressa. 2002. 187p. Dissertação (Mestrado em Geografia) - Faculdade de Filosofia, Letras e Ciências Humanas, Universidade de São Paulo, 2002.

BURKE, Peter. O Que é História Cultural? Rio de Janeiro: Jorge Zahar Ed., 2005.

CANCLINI, Nestor Garcia. Culturas Híbridas. México, Editorial Guijalbo, 1990.

FARIAS, Cleodon Marques. Entrevista. Entrevista concedida à Tafinis Said em 15 de Dezembro, 2016/ vídeo,30min. Boa Vista,2016.

FIGUEIRA BORGES, E. J.; BAPTAGLIN, L. A. Caminhos narrativos dos rappers de Boa Vista (RR). Aturá - Revista Pan-Amazônica de Comunicação, v. 2, n. 2, p. 261-275, 23 abr. 2018.

FLUSSER, Vilén. Filosofia da caixa preta: Ensaio para uma futura filosofia da fotografia. Editora HUCITEC. São Paulo. 1920. 92p. 


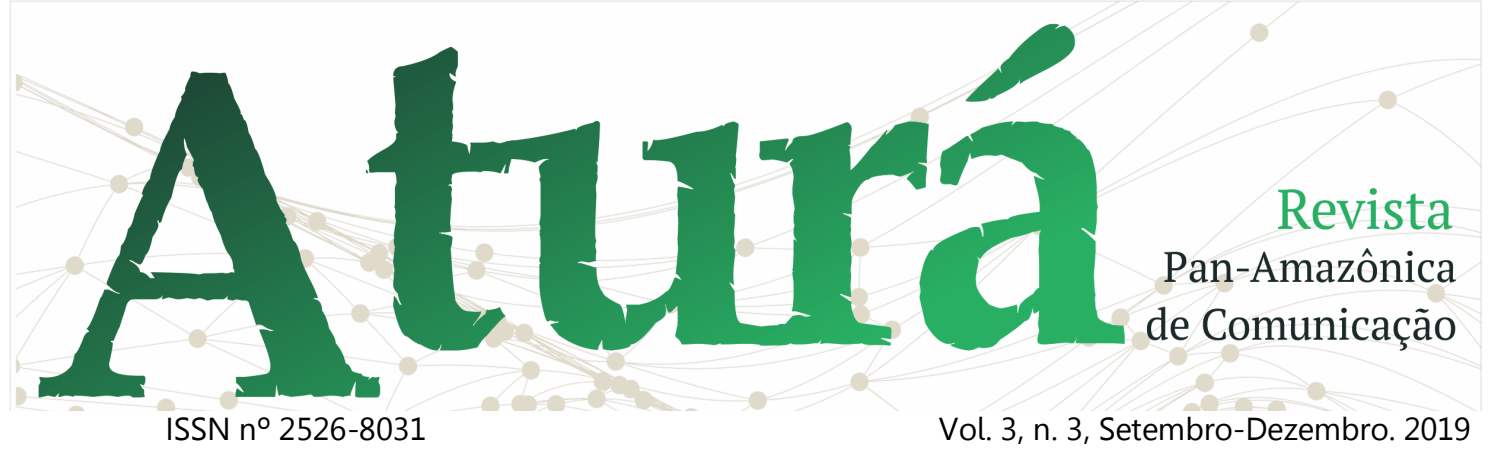

FREITAS, Aibere. A história e Geografia de Roraima. 9. Ed. Boa Vista: Editora IAF, 2017.

GIL, Antônio Carlos. Métodos e técnicas de pesquisa social. 4.ed.São Paulo: Atlas,1994.

GOMES, J. M. DE J.; BAPTAGLIN, L. A. Heróis e heroínas no circum-roraima: a transposição de personagens das textualidades de origem indígena e afrodescendente para outros campos discursivos na Venezuela. Aturá - Revista Pan-Amazônica de Comunicação, v. 2, n. 1, p. 275-293, 11.

JUNIOR, Azevedo José Garcia de. Apostila de Arte -Artes Visuais. São Luís: Imagética Comunicação e Design, 2007.

KUHN, Thomas S. A estrutura das revoluções científicas. São Paulo: Perspectiva,1962.

LOPES, Maria Immacolata. Pesquisa em Comunicação. São Paulo: Loyola, 2003.171p.

MARTINS, Elisangela. Memória do Regime Militar em Roraima. 2010. Dissertação (Mestrado em História) - Universidade Federal do Amazonas, Manaus,2010.

NORA, Pierre. Entre memória e história; a problemática dos lugares. In: Revista do
Programa de Estudos Pós-Graduados de História, 1993. Disponível em: <http://revistas.pucsp.br/index.php/revph /article/viewFile/12101/8763>Acesso em: 03 março 2015.

POLLAK, Michael. Memória e identidade social. Estudos Históricos, Rio de Janeiro, vol. 5, n. 10, 1992, p. 200-212.

SANTOS, B. S. Descolonizar el saber reinventar el poder. Montevideo: Ediciones Trilce, 2010. (p. 07- 60)

SANTOS, Boaventura de Sousa; MENESES, Maria Paula. (Orgs.) Epistemologias do Sul. São. Paulo; Editora Cortez, 2010. p. 637.

SILVA, M. V. F. DA; BAPTAGLIN, L. A. Migrantes em boa vista: subjetividade da música gaúcha presente nas manifestaç̃̃es juninas boa-vistense. Aturá - Revista Pan-Amazônica de Comunicação, v. 1 , n. 3, p. 162-174, 10 dez. 2017.

SOUSA, W. C.; BAPTAGLIN, L. A. Relações indentitárias $O$ aluno indígena na universidade. Aturá - Revista PanAmazônica de Comunicação, v. 3, n. 2, p. 86-96, 1 maio 2019. 